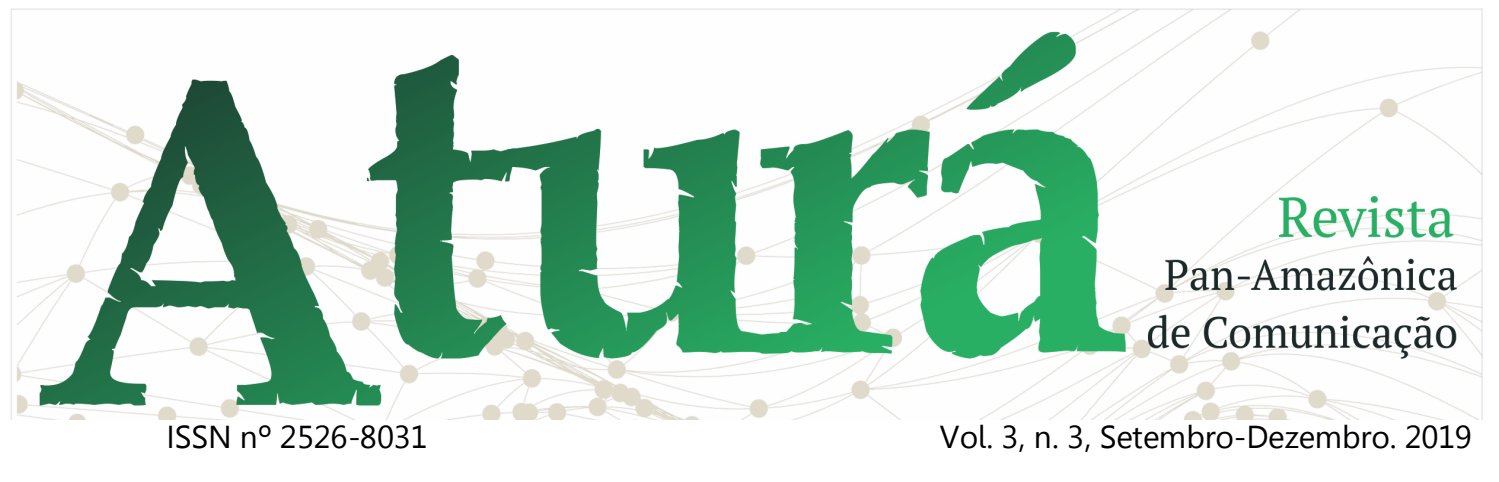

\title{
ENSINO E FORMAÇÃO EM JORNALISMO: POR QUE INSISTIR NO ENSINO DE SOCIOLOGIA?
}

TEACHING AND TRAINING IN JOURNALISM: WHY INSIST ON SOCIOLOGY TEACHING?

\section{ENSEÑANZA Y FORMACIÓN EN PERIODISMO: ¿POR QUÉ INSISTIR EN LA ENSEÑANZA DE SOCIOLOGÍA?}

Joselinda Maria Rodrigues ${ }^{1}$

Francisco Gilson Rebouças Porto Junior ${ }^{2}$

\section{RESUMO}

O ensino de sociologia nos cursos de comunicação e jornalismo tem sido criticado, removido e perde espaço nos espaços formativos. Nesse cenário, a pesquisa qualitativa e documental, base desse artigo, sobre o ensino de sociologia, aconteceu entre 10 docentes, 05 de universidades brasileiras e 05 de universidades portuguesa. Procedeu do exame dos projetos pedagógicos dos cursos de comunicação e jornalismo de 02 universidades brasileiras e 05 universidades portuguesas; da pesquisa dos programas da disciplina sociologia para verificar se o enfoque que é dado nos três campos das ciências sociais se devia a especificidades das próprias universidades e se sofriam interferências internas e externas, e da verificação da metodologia de ensino da sociologia cruzando as bibliografias utilizadas, antes e depois das novas Diretrizes Curriculares de Jornalismo (no Brasil) e do

\footnotetext{
${ }^{1}$ Socióloga, mestre em Comunicação e Sociedade pelo PPGCOM-UFT. E-mail: jomariarodrigues1@gmail.com. 2 Doutor em Comunicação e Cultura Contemporâneas pela Faculdade de Comunicação da Universidade Federal da Bahia (UFBA), mestre em Educação pela Faculdade de Educação (UnB) e graduado em Comunicação Social/Jornalismo (ULBRA) e Pedagogia (UnB). Líder do Núcleo de Pesquisa e Extensão e Grupo Lattes Observatório de Pesquisas Aplicadas ao Jornalismo e ao Ensino (OPAJE-UFT). É professor na Fundação Universidade Federal do Tocantins (UFT). E-mail: gilsonporto@uft.edu.br.
} 


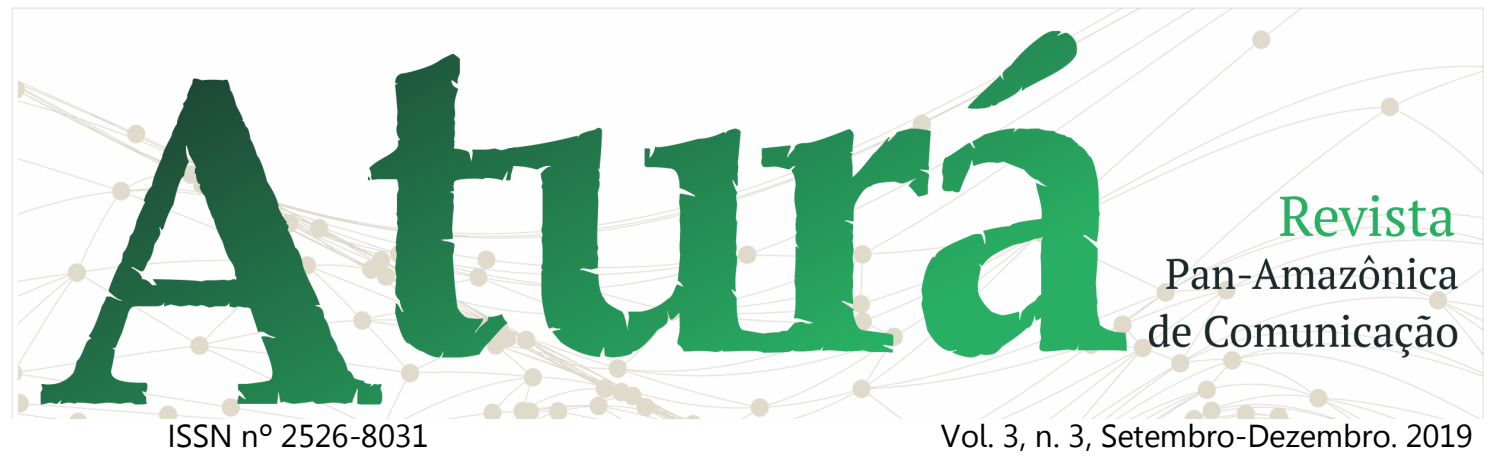

Processo de Bolonha (em Portugal), com o objetivo de entender as escolhas bibliográficas de autores clássicos e contemporâneos.

PALAVRAS-CHAVE: Ensino. Sociologia. Comunicação. Jornalismo.

\begin{abstract}
The teaching of sociology in the courses of communication and journalism has been criticized, removed and loses space in the training spaces. In this scenario, the qualitative and documentary research, the basis of this article, in the teaching of sociology, was carried out among 10 professors, 05 from Brazilian universities and 05 from Portuguese ones. Proceeded to examine the pedagogical projects of communication and journalism courses of 02 Brazilian universities and 05 Portuguese universities; of the research of the programs of the sociology discipline to verify if the approach that takes place in the three fields of the social sciences was due to the specificities of the universities themselves and if they suffered internal and external interferences and the verification of the methodology of teaching of sociology crossing the bibliographies used, before and after the new curriculum Journalism Guidelines (in Brazil) and the Bologna Process (in Portugal), in order to understand the options literature of classical and contemporary authors.
\end{abstract}

KEYWORDS: Teaching. Sociology. Communication. Journalism.

\title{
RESUMEN
}

La enseñanza de la sociología en los cursos de comunicación y periodismo ha sido criticada, eliminada y pierde espacio en los espacios formativos. En este escenario, la investigación cualitativa y documental, basada en este artículo, sobre la enseñanza de la sociología, tuvo lugar entre 10 profesores, 05 de universidades brasileñas y 05 de universidades portuguesas. Procedió a examinar los proyectos pedagógicos de los cursos de comunicación y periodismo de 02 universidades brasileñas y 05 universidades portuguesas; desde la investigación de los programas de disciplina de sociología para verificar si el enfoque dado en los tres campos de las ciencias sociales se debió a las especificidades de las propias universidades y si sufrieron interferencia interna y externa, y la verificación de la metodología de enseñanza de la sociología que cruza las bibliografías utilizadas, antes y después de las nuevas 


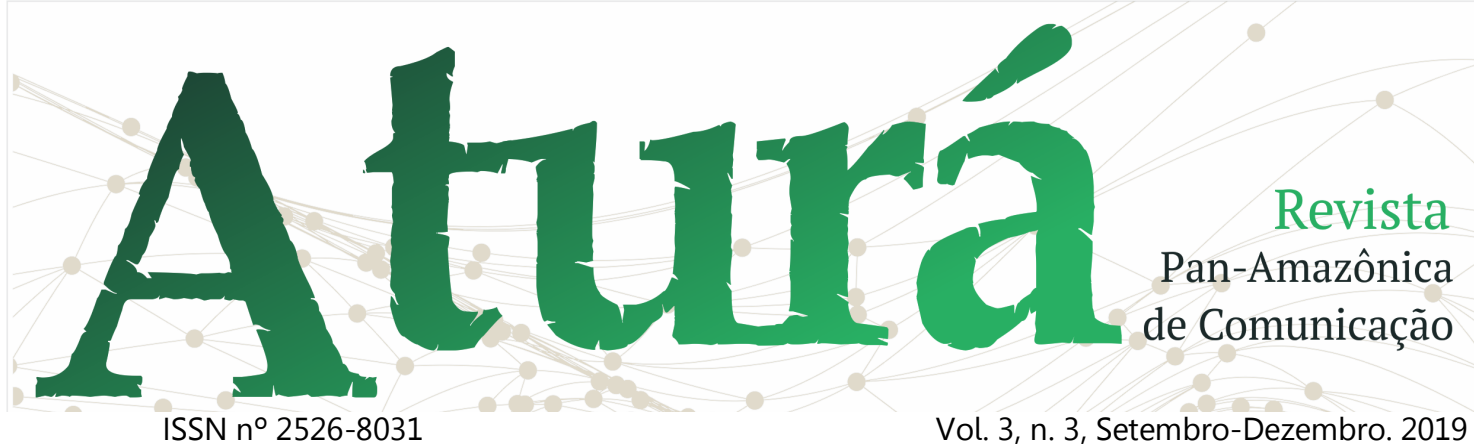

Directrices curriculares para el periodismo (en Brasil) y el Proceso de Bolonia (en Portugal), para comprender las opciones bibliográficas de los autores clásicos y contemporáneos.

PALABRAS CLAVE: Docencia. Sociologia Comunicación. Periodismo.

Recebido em: 19.06.2019. Aceito em: 09.08.2019. Publicado em: 01.09.2019. 


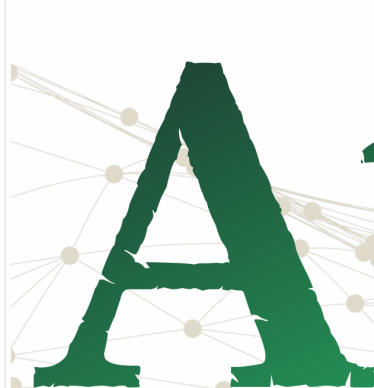

ISSN n² 2526-8031

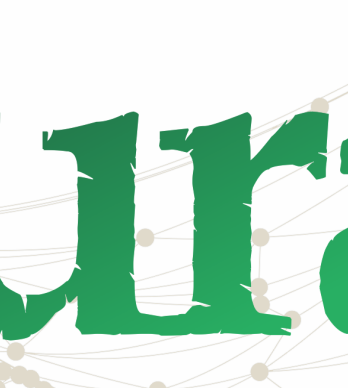

Vol. 3, n. 3, Setembro-Dezembro. 2019

\section{INTRODUÇÃO}

Os principais temas da sociologia parecem atemporais. Do ponto de vista da sociologia tradicional os objetos de investigação de Durkheim, Marx e Weber continua em alta, sem prazo de validade. São inúmeros os fatos sociais sobre os quais jornalistas dos dois hemisférios se debruçam na tentativa de entendê-los para poder interpretar.

Talvez no momento desta leitura a mente vaguei à procura de acontecimentos que têm tomado de assalto a sociedade brasileira. Para refrescar a memória tome como exemplo o desenrolar dos acontecimentos no estado do Rio de Janeiro. Que indivíduo não fica estarrecido diante da falência das instituições públicas? Se a base dessa reflexão se limitar à quantidade de crianças que foram mortas pela violência nos últimos meses, o indivíduo pode fazer uma conta rápida e chegar aos seguintes resultados chocantes: Maria Eduarda, Vanessa, Arthur, Emily Sofia, Lorena, Vitor Gabriel e Eduardo Henrique eram crianças cujas mortes exigem algum tipo de explicação racional. Há explicação?

A onda de violência que assola o país pode estar associada ao desemprego. Faltou trabalho para 26,4 milhões de brasileiros no mês de fevereiro de 2018, conforme pesquisa divulgada pelo Instituto Brasileiro de Geografia e Estatística - IBGE. E essa violência atinge diversos estratos sociais e situações sociais. (SANTOS; MEDINA, 2018; COSTA; BRAGA; PINHO; KABUENGE, 2018; SILVA; SOUSA; BORGES, 2015; MANSO; MELLO; LOPES, 2018; CÔRTE; SANTOS, 2018; MIRANDA, 2017; LIMA; TEMER, 2016; MELO; PORTO JUNIOR, 2017; SIMÕES; LIMA， 2018; BATISTA; MACIEL, 2018; THURLER，2017; SARAIVA，2018; KLEIN; PARENTE, 2017; GREGOLI, 2017).

Esse exército de desempregados, pode favorecer o surgimento da anomia, que tanto no conceito de Durkheim, está relacionada à falta de objetivos, resultante da desestruturação social, das normas préestabelecidas de convívio social e dentre elas as que até então regeram o mundo do trabalho; quanto no conceito de Merton, 


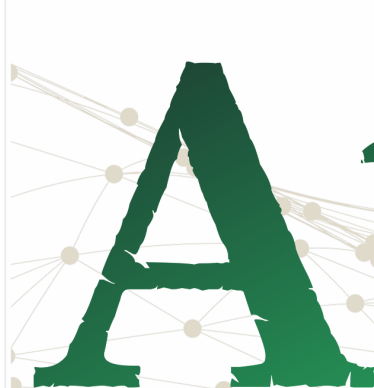

ISSN n² 2526-8031
Revista

Pan-Amazônica

de Comunicação

Vol. 3, n. 3, Setembro-Dezembro. 2019 que também na falta de objetivos, pela falência dos meios providos pelas instituições, a anomia se instala provocando desregulação, principalmente nas classes baixas, as quais são rapidamente afetadas pelas crises econômicas e sociais. (DURKHEIM, 1999; MERTON, 1968).

Karl Marx previu nos seus estudos que quanto mais o capitalismo se sofisticasse, piores as condições de trabalho ou como acontece no Brasil, inexistência de trabalho para milhões de pessoas. Passados 174 desde que Marx tratou da alienação do trabalho, o que se vê no mundo do trabalho é a mais completa desestruturação das garantias trabalhistas. A precarização do trabalho ultrapassa as fronteiras nacionais, provocando a curto, médio e longo prazo o empobrecimento paulatino da classe trabalhadora, que vê os postos de trabalho minguando. A atual situação é um déjà vu da frase: "O trabalhador não tem apenas de lutar pelos seus meios de vida físicos,

\footnotetext{
${ }^{3}$ Ricardo Antunes é autor do livro O mundo do
} trabalho e se ressai no Brasil e exterior discutindo ele tem de lutar pela aquisição de trabalho, isto é, pela possibilidade, pelos meios de poder efetivar sua atividade." (MARX, 2004, p. 25).

Ricardo Antunes ${ }^{3}$, falando sobre a desestruturação do trabalho no Brasil, que a reforma trabalhista causará, foca no empobrecimento paulatino dos trabalhadores, em queda descendente como acontece na Índia terceirizada. Para o autor, a desregulamentação das relações de trabalho gerará maiores índices de violência como resultado do desemprego que tende a aumentar. Antunes vê com pessimismo crescente a expansão do zerohour contract, pela falta de compromisso do empregador com o empregado. Nesse tipo de relação de trabalho, o empregador contata 0 trabalhador para aquela atividade específica, sem que haja nenhum vínculo empregatício. Ambos podem declinar do compromisso sem "nenhum" ônus. É a institucionalização do freelance, atividade mais penosa para o trabalhador que a própria terceirização. Segundo

as lutas históricas do trabalhador e da alienação do trabalho. 


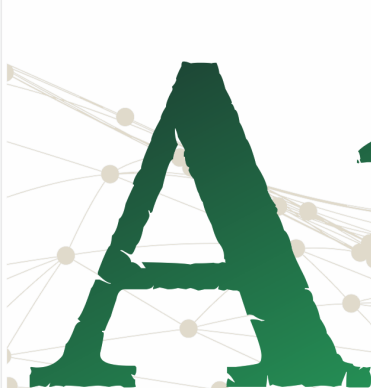

ISSN n² 2526-8031
Revista

Pan-Amazônica

de Comunicação

Vol. 3, n. 3, Setembro-Dezembro. 2019

estimativa a Inglaterra possui mais de um milhão de trabalhadores zero-hour contract, modalidade de ocupação que já é exportada para o Brasil. Todavia, explicações de fatos sociais como a desmantelação das relações de trabalho não dão conta sozinhas, de explicar para a sociedade a racionalidade capitalista que pauta suas ações.

A "ação social racional com relação a fins" (zuechrationale Deutung), faz parte da teoria weberiana de que as ações dos indivíduos são motivadas por determinados objetivos. Nesse contexto de trabalho desestruturado, imagina-se que o objetivo do capitalismo é auferir maiores lucros com menores custos, desconsiderando-se os custos sociais de sua ação. Embora Weber não discuta motivações, interessa-se em compreender o sentido das ações individuais, porque as ações guardem subjetividades. (WEBER, 1993).

Resta lembrar que ações individuais afetam o coletivo, ou seja, indivíduo e sociedade são indissociáveis. Defende-se assim, o ensino de sociologia porque dentro das ciências sociais, como disciplina humanística, completa a formação do profissional em jornalismo que como o sociólogo, lida com situações que do ponto de vista da racionalidade são incompreensíveis (WEBER, 1993), mas que podem ser interpretadas à base da antropologia, ciência política, história, psicologia e sociologia.

As considerações acima querem acentuar a contemporaneidade das teorias durkheimiana, marxista e weberiana, teorias base da sociologia, que não prescreveram apesar de seus quase dois séculos de existência. Teóricos clássicos e contemporâneos da sociologia fazem parte dos programas das disciplinas dos cursos de comunicação e jornalismo embora o ensino teórico esteja sob ataque dos defensores de sua retirada das matrizes curriculares.

O artigo apresenta a perspectiva docente quanto ao ensino da sociologia e sua metodologia. 


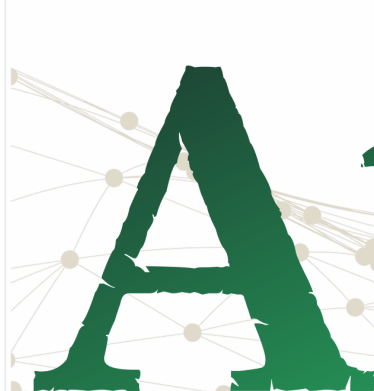

ISSN n $2526-8031$
Revista

Pan-Amazônica

de Comunicação

Vol. 3, n. 3, Setembro-Dezembro. 2019

2 A CRÍTICA QUANTO A GRANDE CONCENTRAÇÃO DE MATÉRIAS TEÓRICAS NO CURSO DE COMUNICAÇÃO

Considerando-se a liberdade de expressão como uma das características indeléveis da democracia, a importância da mídia fica mais premente por sua capacidade de persuasão junto à opinião pública, que para Sartori (1994), além de ser uma opinião compartilhada pelo público está vinculada a interesses públicos, à res pública. Entende-se a responsabilidade de a mídia neste aspecto, diante da defesa de Sartori (1994, p. 125), de que além da defesa de interesses públicos está o direito de o público ser informado sobre as coisas públicas, informações possíveis apenas pelo advento da "imprensa, de notícias e de jornais."

Os meios de comunicação, de acordo com Sartori (1994) fazem parte do segundo patamar do efeito cascata de formação da opinião, efeito vantajoso por facultar democraticamente o alimentar de informações de seu patamar, independentemente das polarizações que as mensagens enviadas possam causar, tão grande seu poder de penetração junto às massas. Diante da responsabilidade que os media adquiriram desde o surgimento do jornal, a qualidade da formação acadêmica é essencial se o jornalista há de desempenhar bem o seu papel de "informante da sociedade" e como processo formativo entende-se que $\mathrm{o}$ corpo teórico e técnico da universidade deve abastecer o futuro jornalista de conhecimentos, de modo que ele dê conta das demandas por informação que a sociedade mutante do século XXI apresenta.

Espera-se que a universidade como espaço de produção de conhecimento, proveja preparo profissional, não apenas técnico e utilitarista, mas do tipo polimorfo, ao qual é indispensável o arcabouço teórico (LARANJEIRA, QUADROS E CAETANO, 2011).

Questionar polarizações entre teoria e técnica é uma prática saudável no ensino (PORTO JUNIOR; MORAES, 2017; MOTA; FERREIRA, 2017; NUNES; PORTO JUNIOR; MORAES, 2017). Há algum tempo 


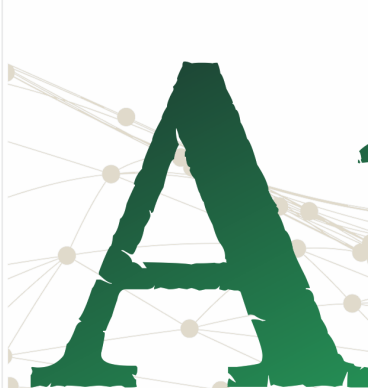

ISSN n² 2526-8031
Revista

Pan-Amazônica

de Comunicação

Vol. 3, n. 3, Setembro-Dezembro. 2019

reclama-se do excesso de carga teórica no curso de comunicação. Diz-se que o jornalismo se faz com prática e a insistência na teoria é um mecanismo encontrado pelas universidades para dar vazão aos quadros docentes de humanas.

Jornalistas portugueses, por exemplo, segundo o estudo de Teixeira (2010), se queixavam do jornalismo acadêmico desde sua criação, sendo depreciado por não possuir um corpo docente que ensinasse as técnicas jornalísticas. Sob esse ponto de vista, a academia não estava habilitada para formar os futuros jornalistas.

Dessa forma, críticas contra a presença de matérias teóricas no curso de comunicação, podem ser reflexo da formatação que a mídia imprimiu às comunicações ou reflexo da precarização do trabalho jornalístico, que como foi dito na introdução afeta todas as atividades. $O$ comunicólogo formado na academia, inserido no mercado de trabalho, pode constatar que desperdiça suas potencialidades ao produzir informação sem conteúdo comunicacional, conforme o modelo vigente de notícias rápidas, porém, precisa fazê-lo, uma vez que os veículos dependem da audiência, se quiserem a fidelidade dos anunciantes, e $o$ jornalista, do emprego (MELO, 2017; TEIXEIRA; SILVA; MARTINS, 2017; ALVES; SILVA, 2017; MOIO; ALCOFORADO; VIEIRA, 2017; REIS, 2017; PINHO, 2017).

As técnicas de redação, o uso das tecnologias e a linguagem digital são pelo menos no mundo ocidental, universais, apresentando talvez mínimas variações. Os meios de comunicação têm mínima variação de objetivos, mas o sentido da comunicação, esse sim constrói a teia de significados, que é a cultura, a qual pode apresentar diferenças substanciais mesmo dentro do próprio país, como acontece no Brasil.

Os significados subjetivos da comunicação com as dificuldades de compreensão do que é dito, aparece para Wolton (2004, p. 30-31), como "uma das grandes revelações e contradições do século XX", ampliadas pelas grandes migrações do século XXI. A técnica, por não vislumbrar soluções, "devolve" o 


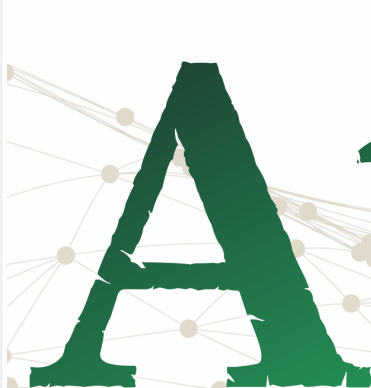

ISSN n² 2526-8031
Revista

Pan-Amazônica

de Comunicação

Vol. 3, n. 3, Setembro-Dezembro. 2019

problema para teorias ancoradas na antropologia, ciência política, filosofia, história, sociologia e psicologia.

\section{A DEFESA DE UM BOM EMBASAMENTO TEÓRICO QUE PODERÁ AJUDAR O FUTURO JORNALISTA NO DESEMPENHO DA PROFISSÃO.}

Compreender $\circ$ mundo para trabalhar com comunicação pode requerer esforços estrênuos para os que forem formados apenas em bases tecnicistas crendo que a técnica dá conta de questões subjetivas. Obviamente, as TICS obrigaram mudanças no formato das comunicações e é louvável que as instituições tenham se adequado ou estejam se adequando a elas, entretanto, convém aos espaços formativos estarem alertas ao que parece uma benesse da convergência, mas que pode ser uma forma de intromissão demasiada do mercado no espaço acadêmico, portanto, o equilíbrio pode ser um inestimável argumento contra a concentração de disciplinas.

Fidalgo (2001), antenado com as tecnologias digitais entende que mesmo diante das novas tecnologias de comunicação, os alunos ainda precisam de embasamento teórico. O contato diário com as tecnologias digitais "ensina" aos alunos duas verdades importantes: $1^{\mathrm{a}}$. As novas TICS exigem a mesma preparação teórica que os antigos meios de comunicação exigiam e $2^{\mathrm{a}}$., ainda exigem o componente intelectual e criativo, que para o autor, é mais difícil que o componente técnico. Esse relacionar as duas coisas ou interdisciplinaridade é o objetivo de dez em dez instituições de ensino, mas de difícil consecução, ainda assim, ela se mostra como a forma mais próxima de os alunos aprenderem como usar a teoria para desenvolver a técnica.

Tendo em vista a argumentação de Fidalgo parece pertinente "ouvir" as vozes dos professores entrevistados quanto a aplicação da sociologia nas diferentes disciplinas que lecionam.

\section{TRÊS HIPÓTESES SOBRE O ENSINO DE SOCIOLOGIA}

A diversidade dos projetos políticos pedagógicos dos cursos de comunicação 


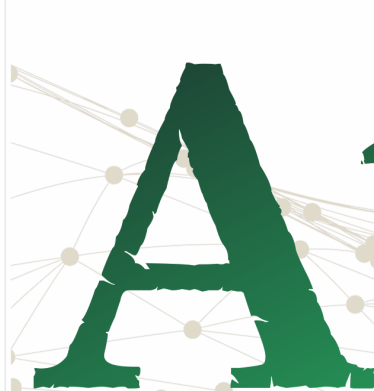

ISSN n $2526-8031$
Revista

Pan-Amazônica

de Comunicação

Vol. 3, n. 3, Setembro-Dezembro. 2019

e jornalismo, em alguns cursos faculta ao estudante o estudo de sociologia. Isso pode anuviar seu critério ético, concorrendo para o falso discurso no jornalismo, contudo, o ensino da sociologia pode embasar o referencial teórico do estudante ao ajudá-lo a estabelecer, ele próprio, parâmetros do que é verdadeiro ou falso, e do papel que ele, enquanto intérprete da realidade desempenha para o consumidor do produto jornalístico.

O sistema midiático baseado na competitividade administra os conteúdos no sistema just in time tinduzindo as $^{4}$ universidades a priorizarem a técnica jornalística e consequente enxugamento de estruturas curriculares, consequentemente, o curso de comunicação e jornalismo habilita o estudante a suprir-se de informações profusamente disponíveis, as quais devem

4 A expressão just in time faz referência ao Toyotismo, na sua forma de gerência de tempo e recursos estritamente necessários à produção. A autora recorre à expressão por supor que as ser analisadas e repassadas em espaços cada vez mais curtos de tempo.

A comunicação no século XXI está baseada nas Tecnologias de Informação e Comunicação, caracterizadas pela velocidade de processamento.

dinamismo que a internet dotou as várias formas de comunicação urge também dinamismo similar no ensino de sociologia que pode ser dinamizado pela substituição de bibliografias hard por autores mais contemporâneos que auxiliem no entendimento das grandes questões que se apresentam neste início de século.

\section{O QUE DIZEM E FAZEM OS PROFESSORES}

A descoberta de que o ensino da sociologia em cursos de comunicação e jornalismo não era obrigatório nas instituições de ensino embora as áreas de estudo fossem próximas e por ser a

matrizes curriculares das universidades parecem ter sido criadas para atender às exigências do alunado e mercado por cursos de graduação que atendam às suas necessidades em tempo justo. 


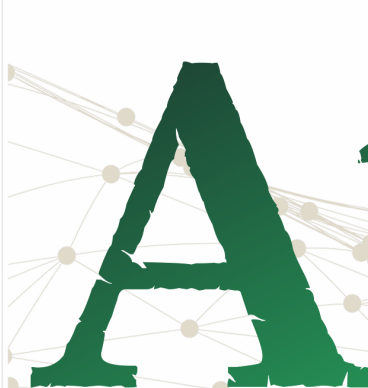

ISSN n² 2526-8031
Revista

Pan-Amazônica

de Comunicação

Vol. 3, n. 3, Setembro-Dezembro. 2019 comunicação imprescindível nas relações sociais provocou os questionamentos que deram origem a essa pesquisa. A pesquisa sobre os teóricos e teorias utilizados pelos docentes entrevistados revelou que mesmo na ausência das ciências sociais nas matrizes curriculares - com foco na sociologia e sociologia da comunicação, utilizam-se suas bases e de outras ciências humanas em saudável hibridação, que segundo Canclini (1998), é a combinação de processos socioculturais, que juntos dão nova forma a práticas pré-existentes.

Os docentes entrevistados entendem unanimemente que mesmo na ausência da disciplina sociologia nas matrizes curriculares do curso de comunicação ou da falta de espaço para inclusão direta das teorias sociológicas nos seus programas de ensino, é necessário entremear o conteúdo de suas disciplinas com as ciências da sociedade mesmo na presença de disciplinas técnicas. Os professores são todos protagonistas de metodologias de ensino que visam, claro os conteúdos disciplinares, mas que demonstram absoluta preocupação com as questões inerentes à profissão do jornalista como as que a pesquisadora apreendeu de suas falas como:

1. A necessidade de o aluno aprender a pesquisar desde os semestres iniciais, dissociando a pesquisa da ideia de fardo; associando a pesquisa qualitativa - incidente no jornalismo a um referencial teórico consistente.

2. A disposição de os professores ajudarem no crescimento intelectual de seus alunos, atentos às pressões do mundo do trabalho e suas demandas, porém ressaltando a dimensão social do jornalismo.

3. A percepção de que o aluno se sairá melhor se entender que o estudo das teorias subsidiará a prática; que olhar a realidade sob o prisma sociológico pode ajudá-lo na contextualização dos problemas sociais.

4. A ênfase nos relacionamentos existentes entre a sociologia, a 


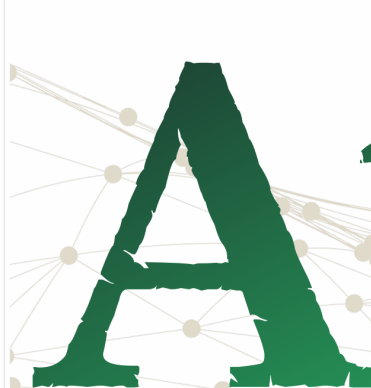

ISSN n² 2526-8031
Revista

Pan-Amazônica

de Comunicação

Vol. 3, n. 3, Setembro-Dezembro. 2019 comunicação, os media e as Tecnologias da Informação e Comunicação - TICS.

5. A proteção contra o entorpecimento político e social que o conhecimento provido pelas ciências sociais dá ao indivíduo.

6. A conscientização ao alunado de que a omissão do ensino de ciências sociais serve a interesses outros, e não os interesses do futuro jornalista.

Entende-se assim, que o ensino da sociologia pode embasar o referencial teórico do estudante de comunicação e ajudá-lo a estabelecer padrões de conduta profissional em benefício próprio e do consumidor da notícia.

Outra preocupação nessa pesquisa foi a desconfiança de que a universidade é pressionada a enxugar as matrizes curriculares dos cursos de comunicação e jornalismo e privilegiarem conteúdos técnicos. Essa desconfiança baseou-se em leituras sobre a indústria cultural e os produtos que destina ao público de classes populares que suplantam "a luz", do esclarecimento que apenas a cultura pode suprir. A indústria cultural "vende" a falsa ilusão de liberdade de escolha, no entanto, induz ao consumo de seus produtos através da mídia e dos media (ADORNO, 2002; BAUMAN, 2001).

O mercado exerce pressão indireta na universidade de duas maneiras. A primeira maneira ocorre quando 0 mercado absorve o aluno/candidato. Isso diz à universidade que ela está satisfazendo sua necessidade. Segundo um dos professores entrevistados, os espaços formativos se conformam à economia do conhecimento de nosso tempo, onde os conhecimentos estão a serviço da economia. A segunda maneira quando retorna o aluno/candidato. $\mathrm{O}$ retorno diz à universidade que ela não está correspondendo às suas expectativas. Tanto no Brasil quanto em Portugal há balcões de emprego que servem de filtro para o "produto" que a universidade deve preparar. Então, sob esse ponto de vista, o mercado exerce pressão indireta sobre os espaços formativos. 


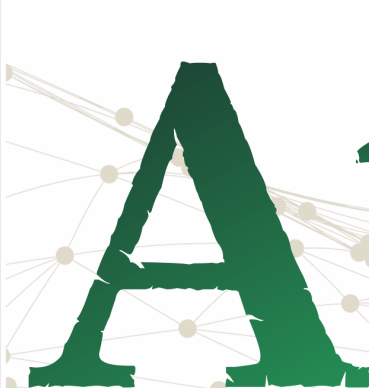

ISSN n² 2526-8031
Revista

Pan-Amazônica

de Comunicação

Vol. 3, n. 3, Setembro-Dezembro. 2019
A recorrência do sistema just in time para o curso de comunicação flui do corpo discente preocupado com as vagas de emprego minguantes e suas necessidades econômicas. De maneira geral, o aluno tem pressa para graduar estritamente por questões econômicas o que também explica a relação estabelecida com as disciplinas teóricas. Sob seu ponto de vista, elas retardam sua saída da universidade.

É a pressa do aluno em entrar no mercado de trabalho que 0 faz menosprezar as disciplinas teóricas. Professores brasileiros e portugueses de disciplinas técnicas e teóricas "bebem moderadamente" das bibliografias hard. Ao usá-las, são entremeadas com autores contemporâneos e outros tipos de sociologia que surgiram à medida que as sociedades evoluíram. Há uma feliz flexibilidade docente antenada com as mudanças que as Tecnologias da Informação e Comunicação - TICS imprimiram ao processo comunicacional e que adaptaram as bibliografias às especificidades dos cursos como em uma espécie de "dízimo epistemológico" conforme sugerido por Morin (2003).

Os docentes brasileiros e portugueses, a pesquisa revela, por entenderem a responsabilidade da mídia enquanto alimentadora das massas, são sensíveis à necessidade de os estudantes inteirarem-se das questões pertinentes à sociedade, e da importância do equilíbrio entre teoria e prática. Reconhecem e entendem a urgência da maioria dos estudantes de ingressar no mercado de trabalho por questões preponderantemente econômicas, isto é, a exiguidade de vagas nas empresas de comunicação, imprimem um ritmo de estudo acelerado, o qual, para muitos alunos parece ser retardado pela teoria, e por esse motivo objetam sua presença.

No Brasil, os docentes aproveitam os conhecimentos prévios dos alunos, destacando-se os digitais, pela natureza do curso, para mostrar que autores clássicos e contemporâneos podem ser revisitados para ampliar o escopo de conhecimentos. Em Portugal a prática é semelhante, com a vantagem de $\mathrm{o}$ 


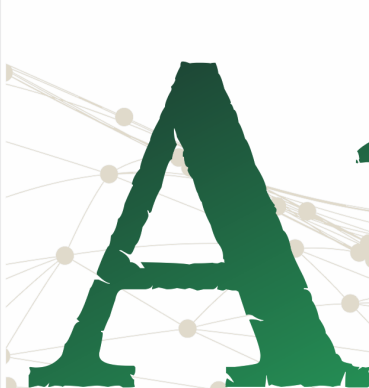

ISSN n² 2526-8031
Revista

Pan-Amazônica

de Comunicação

Vol. 3, n. 3, Setembro-Dezembro. 2019

aprendizado ao longo da vida - lifelong learning ${ }^{5}$, como fundamento do Processo de Bolonha, além de ser aproveitado didaticamente nas interações professoraluno, também servem como créditos acadêmicos. Os docentes se preocupam com a contextualização do ensino oferecido, que esteja de acordo com as novas tendências pedagógicas, de aliarem-se teoria e técnica quando possível.

\section{CONCLUSÃO}

Portanto, a pesquisa revelou processos dinâmicos no ensino de sociologia quando professores sociólogos da disciplina sociologia privilegiam teorias contemporâneas respaldadas pelas teorias clássicas. Também, que professores jornalistas de disciplinas técnicas utilizam autores e conceitos da sociologia nos seus cursos para embasar conhecimentos técnicos. As atitudes dos

\footnotetext{
${ }^{5}$ Aprendizado ao longo da vida - lifelong learning refere-se ao aproveitamento das diversas habilidades que o indivíduo adquire ao longo da vida, seria uma forma de o continente agregar ao
}

professores revelam a existência de bastante espaço para a inserção da sociologia na comunicação e jornalismo.

A pesquisa revelou também que investigações sobre $\mathrm{O}$ ensino de comunicação e jornalismo são incipientes e inexistentes em se tratando do ensino de sociologia e/ou sociologia da comunicação em cursos de comunicação e jornalismo.

\section{REFERÊNCIAS}

ADORNO, T. W. Indústria cultural e sociedade. Seleção de textos. Jorge Mattos Brito de Almeida traduzido por Juba Elisabeth Levy...[eta1.]. São Paulo: Paz e Terra, 2002. Disponível em:< file://C:/Users/gomes/AppData/Local/Te mp/Temp3_Sociologia\%20do\%20Jornalis mo.zip/ADORNO,\%20T.\%202009.\%20Ind ústria\%20cultural\%20e\%20sociedade\%20 -\%20alunos.pdf>. Acesso 20 jan. 2017.

ALVES, E.; SILVA, B.; SILVA, R.
MAPEAMENTO DOS ESTUDOS SOBRE A

capital cultural os novos conhecimentos que a universidade proveria (BFUG, 2015, p.4; PÔRTO JUNIOR, 2012). 


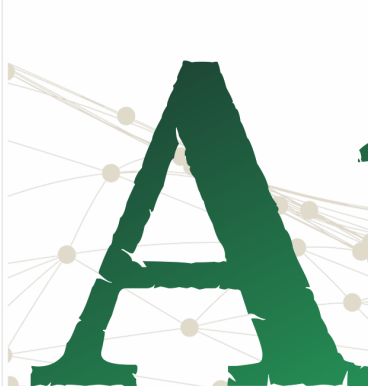

ISSN n² 2526-8031
Revista

Pan-Amazônica de Comunicação

Vol. 3, n. 3, Setembro-Dezembro. 2019
FORMAÇÃO DE PROFESSORES NO ÂMBITO DO PROCESSO DE BOLONHA EM PORTUGAL. Revista Observatório, v. 3, n. 6 , p. 248-273, 1 out. 2017. DOI: https://doi.org/10.20873/uft.24474266.2017v3n6p248.

BATISTA, A.; MACIEL, W. PRISÃO COMO GUETO: a dinâmica de controle e de extermínio de jovens negros pobres. Revista Observatório, v. 4, n. 2, p. 174-200, 1 abr. 2018. DOI: https://doi.org/10.20873/uft.2447-

4266.2018v4n2p174.

BAUMAN, Z. Modernidade líquida. Rio de Janeiro, RJ: Jorge Zahar, 2001.

BFUG. Report of the 2012-2015 BFUG working group on the social dimension and lifelong learning to the BFUG. Disponível em

https://media.ehea.info/file/2015_Yerevan /71/3/Report_of_the_2012-

\section{5_BFUG_WG_on_the_Social_Dimensio} n_and_Lifelong_Learning_to_the_BFUG_61 3713.pdf>. Acesso 01 fev. 2018.

CANCLINI, N. G. Culturas híbridas: estratégias para entrar e sair da modernidade. São Paulo: Edusp, 1998.
COSTA, A.; BRAGA, T.; PINHO, A.; KABUENGE, N. A CONSTRUÇÃO SOCIAL DA VIOLÊNCIA NA AMAZÔNIA PARAENSE: relações discursivas do jornal Correio do Tocantins. Revista Observatório, v. 4, n. 6, p. 293-321, 8 out. 2018. DOI: https://doi.org/10.20873/uft.24474266.2018v4n6p293. CÔRTE, B.; SANTOS, B. EM NOME DO CUIDADO SE NATURALIZA A VIOLÊNCIA: O caso da contenção. Revista Observatório, v. 4, n. 2, p. 279-297, 1 abr. 2018. DOI: https://doi.org/10.20873/uft.2447-

4266.2018v4n2p279.

DURKHEIM, E. Da divisão social do trabalho. $2^{\mathrm{a}}$ ed. - São Paulo: Martins Fontes, 1999. Disponível em < https://edisciplinas.usp.br/pluginfile.php/ 203937/mod_resource/content/1/Da\%20 divis\%C3\%A3o\%20social\%20do\%20trabal ho.\%20\%C3\%89mile\%20Durkheim\%3B\%2 Otradu\%C3\%A7\%C3\%A30\%20de\%20Edua rdo\%20Brand\%C3\%A3o.\%20\%202\%C2\%AA\%20ed.\%20\%20S\%C3\%A3०\%20Paulo\%2C\%20Martins \%20Fontes\%2C\%201999.\%20\%281\%29.p df>.Acesso 01 fev. 2017. 


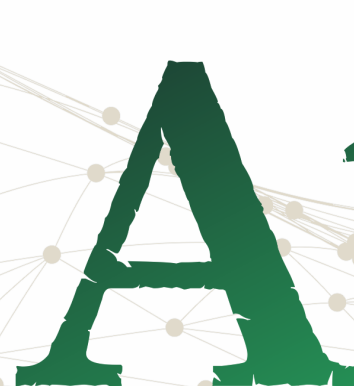

ISSN n² 2526-8031
Revista

Pan-Amazônica

de Comunicação

Vol. 3, n. 3, Setembro-Dezembro. 2019
FIDALGO, A. O ensino do jornalismo no e para o século XXI. Comunicação proferida no Congresso Internacional sobre Jornalismo e Internet, Universidade de Coimbra, 28 e 29 de março de 2001. <Disponível em http://www. bocc. ubi. pt [..., 2001 - bocc.uff.br>. Acesso 19 out. 2016.

GREGOLI, R. DE PERNAS PRO AR: uma revolução confinada ao quarto. Revista Observatório, v. 3, n. 1, p. 131-160, 30 mar. 2017.

DOI: https://doi.org/10.20873/uft.24474266.2017v3n1p131.

KLEIN, K.; PARENTE, T. DO BEM-ESTAR AO ADOECIMENTO: O impacto do assédio moral para as mulheres no Brasil. Revista Observatório, v. 3, n. 5, p. 582-605, 1 ago. 2017.

DOI: https://doi.org/10.20873/uft.24474266.2017v3n5p582.

LARANJEIRA, A.; QUADROS, C.; CAETANO, K. O ensino do jornalismo digital: metodologias que constroem uma disciplina. In: $O$ ensino do jornalismo na era da convergência: conceitos, metodologia e estudos de casos no Brasil.
Elias Machado (Org.). Salvador: EDUFBA, 2011. P. 127-149.

LIMA, F.; TEMER, A. C. A VIOLÊNCIA COMO VALOR-NOTÍCIA NA TELEVISÃO GOIANIENSE: Informação $X$ Audiência. Revista Observatório, v. 2, n. 5 , p. 485-509, 25 dez. 2016. DOI: https://doi.org/10.20873/uft.2447-

4266.2016v2n5p485.

MARX, K. Manuscritos econômico e filosóficos. Tradução e notas: Jesus Ranieri. São Paulo: Boitempo Editorial, 2004. Disponível em: $<$ https://marcosfabionuva.files.wordpress. com/2011/08/manuscritoseconc3b4mico-filosc3b3ficos.pdf $>$. Acesso 08 mar. 2018. MANSO, M.; MELLO, R.; LOPES, R. MÍDIAS DIGITAIS E AS INVISÍVEIS VIOLÊNCIAS CONTRA IDOSOS. Revista Observatório, v. 4, n. 2, p. 265-278, 1 abr. 2018. DOI: https://doi.org/10.20873/uft.24474266.2018v4n2p265. MELO, G.; PORTO JUNIOR, F. LIBERDADE DE IMPRENSA SOB AMEAÇA: uma análise dos casos de violência contra jornalistas no Tocantins. Revista Observatório, v. 3, n. 


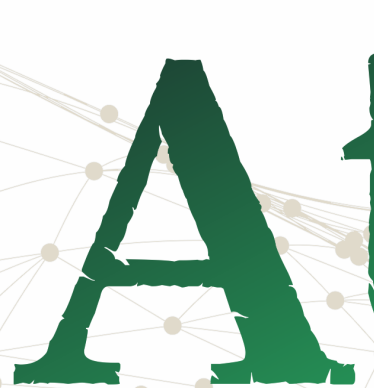

ISSN n०2526-8031
Revista

Pan-Amazônica de Comunicação

Vol. 3, n. 3, Setembro-Dezembro. 2019
1, p. 434-456, 30 mar. 2017. DOI: https://doi.org/10.20873/uft.24474266.2017v3n1p434.

MERTON, R. K. Sociologia: teoria e estrutura. São Paulo, SP: Mestre Jou, 1968. Disponível em: https://csociais.files.wordpress.com/2014/ 05/merton_caps2_3.pdf. Acesso 08 mar. 2018.

MELO, A. ENQUADRAMENTO HISTÓRICO LEGAL DO PROCESSO DE BOLONHA E O SEU IMPACTO NO SISTEMA DE ENSINO SUPERIOR PORTUGUÊS. Revista Observatório, v. 3, n. 6, p. 75-141, 1 out. 2017.

DOI: https://doi.org/10.20873/uft.24474266.2017v3n6p75.

MIRANDA，C. VIOLÊNCIA CONTRA A MULHER NA MÍDIA E OS DESCAMINHOS DA IGUALDADE ENTRE OS GÊNEROS. Revista Observatório, v. 3, n. 6, p. 445-464, 1 out. 2017. DOI: https://doi.org/10.20873/uft.24474266.2017v3n6p445.

MOIO, I.; ALCOFORADO, L.; VIEIRA, C. A DECLARAÇÃO DE BOLONHA E O REFORÇO DA ABERTURA DO ENSINO
SUPERIOR A NOVOS PÚBLICOS: perceções de pessoas adultas que frequentam a Universidade de Coimbra. Revista Observatório, v. 3, n. 6, p. 169-201, 1 out. 2017.

DOI: https://doi.org/10.20873/uft.2447-

4266.2017v3n6p169.

MORIN, E. A cabeça bem-feita: repensar a reforma, reformar o pensamento. Rio de Janeiro: Bertrand Brasil, 2003.

MOTA, L.; FERREIRA, A. A FORMAÇÃO DE PROFESSORES EM PORTUGAL NO QUADRO DO ESPAÇO EUROPEU DE ENSINO SUPERIOR. Revista Observatório, v. 3, n. 6, p. 38-74, 1 out. 2017. DOI: https://doi.org/10.20873/uft.2447-

\subsection{7v3n6p38.}

NUNES, S.; PORTO JUNIOR, F. G. R.; MORAES, N. CONHECIMENTO E ORGANIZAÇÃO: indicativos pós-Bolonha de uma sociedade em construção. Revista Observatório, v. 3, n. 6, p. 338-353, 1 out. 2017.

DOI: https://doi.org/10.20873/uft.2447-

4266.2017v3n6p338.

PÔRTO JUNIOR, F. G. R. Entre Comunicação e Educação: o Processo de 


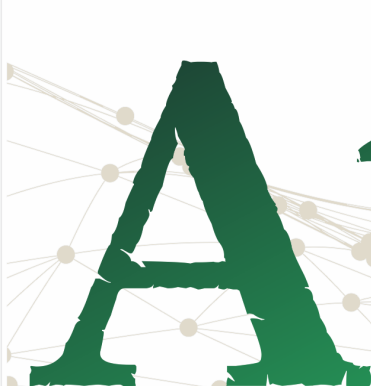

ISSN n² 2526-8031

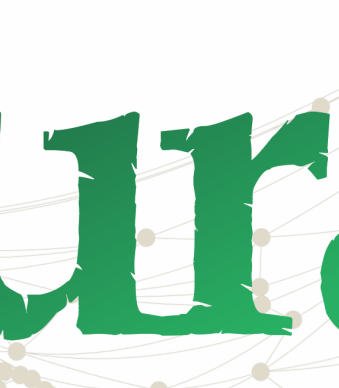

Vol. 3, n. 3, Setembro-Dezembro. 2019
Bolonha e as ações formativas em cursos de Comunicação Social / Jornalismo em Portugal. 2012. 614 f. Tese (Doutorado em Comunicação e Cultura Contemporâneas) Faculdade de Comunicação, Universidade Federal da Bahia, 2012. Disponivel em <http// www.repositorio.ufba.br:8080 >. Acesso em 09 set. 2016.

PORTO JUNIOR, F. G. R.; MORAES, N. FORMANDO PESQUISADORES PÓSBOLONHA EM PORTUGAL: relações entre a formação de graduação e o campo da pesquisa/investigação. Revista

Observatório, v. 3, n. 6, p. 202-228, 1 out. 2017.

DOI: https://doi.org/10.20873/uft.24474266.2017v3n6p202.

PINHO, M. UNIVERSIDADE E CRISE INSTITUCIONAL: perspectivas de uma formação humana. Revista Observatório, v. 3, n. 6, p. 274-315, 1 out. 2017. DOI: https://doi.org/10.20873/uft.24474266.2017v3n6p274.

REIS, E. O ENSINO SUPERIOR EM CABO VERDE E OS DESAFIOS DO PROCESSO DE BOLONHA. Revista Observatório, v. 3, n. 6, p. 142-168, 1 out. 2017.

DOI: https://doi.org/10.20873/uft.2447-

4266.2017v3n6p142.

SARAIVA, R. A REGULAÇÃO DA VIOLÊNCIA MEDIÁTICA EM PORTUGAL. Revista Observatório, v. 4, n. 2, p. 144-173, 1 abr. 2018.

DOI: https://doi.org/10.20873/uft.24474266.2018v4n2p144.

SARTORI, G. A teoria da democracia revisitada. Volume I - 0 debate contemporâneo. São Paulo: Ática,1994.

SANTOS, W.; MEDINA, P. VIOLÊNCIA NA ESCOLA BÁSICA: um estudo de caso envolvendo redes pública e privada em Palmas - TO. Revista Observatório, v. 4, n. 6, p. 794-825, 8 out. 2018. DOI: https://doi.org/10.20873/uft.2447-

4266.2018v4n6p794.

SILVA, J.; SOUSA, R.; BORGES, M. Violência doméstica: análise e correlações do perfil educacional de autores e vítimas na cidade de arraias nos anos de 2012 a 2014. Revista Observatório, v. 1, n. 3, p. 294-316, 26 dez. 2015. DOI: https://doi.org/10.20873/uft.24474266.2015v1n3p294. 


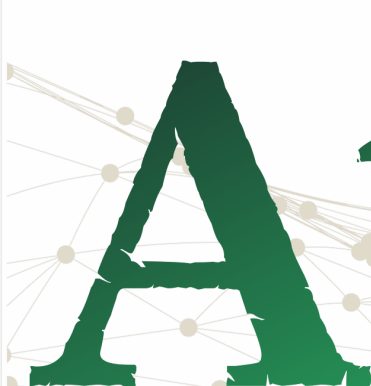

ISSN n² 2526-8031
Revista

Pan-Amazônica

de Comunicação

Vol. 3, n. 3, Setembro-Dezembro. 2019
SIMÕES, P.; LIMA, L. O CASO ELIZA SAMÚDIO COMO ACONTECIMENTO: fama, anonimato e violência de gênero em nossa sociedade. Revista Observatório, $v$. 4, n. 1, p. 599-629, 1 jan. 2018. DOI: https://doi.org/10.20873/uft.2447-

4266.2018v4n1p599.

TEIXEIRA, P. O. $\mathrm{O}$ ensino de jornalismo em Portugal uma história e análise dos planos curriculares. Porto, 2009-2010.Orientador: Prof. Dr. Jorge Pedro Sousa. Dissertação (mestrado). Universidade Fernando Pessoa. 165 f. Disponível em < http://bdigital.ufp.pt/bitstream/10284/16 81/2/DM_19061.pdf>. Acesso 04 set. 2017. TEIXEIRA, I.; DA SILVA, V.; MARTINS, J. A CONVERGÊNCIA MIDIÁTICA E AS TECNOLOGIAS MÓVEIS PÓS-BOLONHA: NOVAS PRÁTICAS SOCIAIS. Revista Observatório, v. 3, n. 6, p. 229-247, 1 out. 2017.
DOI: https://doi.org/10.20873/uft.2447-

4266.2017v3n6p229.

THURLER, A. FEMINICÍDIOS NA MÍDIA E DESUMANIZAÇÃO

DAS MULHERES. Revista Observatório, v. 3, n. 6, p. 465-496, 1 out. 2017. DOI: https://doi.org/10.20873/uft.2447-

\subsection{7v3n6p465.}

WEBER, Max. Metodologia das ciências sociais. 2. ed. São Paulo, SP: Cortez, Campinas, SP: Ed. UNICAMP, 1993. Disponível em file:///C:/Users/gomes/Documents/DEFES A\%20DISSERTA\%C3\%87\%C3\%83O\%20E\% 2OPOWER\%2OPOINT/METODOLOGIA\%20 DAS\%20CI\%C3\%8ANCIAS\%20SOCIAIS.pd f>. Acesso 08 mar. 2018.

WOLTON, D; MOURA, D.; ADGHIRNI, Z. L. Pensar a comunicação. Brasília, DF: Ed. UnB. 2004. 